\title{
When is genetic screening permissible?
}

The World Medical Association is planning to fashion a statement on the ethical principles of genetic screening from a draft that is altogether over-cautious.

THAT there should be general anxiety about the implications of the Human Genome Project (in its many national manifestations) is hardly surprising: the technology is new and will eventually illuminate the physical and even the behavioural constitution of individuals. The Genome Directory published as a supplement to this issue of Nature is a vivid illustration both of how much has been accomplished in the past few years and of how much remains to be done before the databanks contain a complete and representative nucleotide sequence of the human genome. But even when that is done, the task will remain of understanding both the functions of all the genes that will be revealed and the manner in which they are regulated by signals from within and external to the cells containing them. The project is unlikely ever to be complete in a tidy sense, but it will dominate the agenda for research in genetics for decades to come.

For just these reasons, social responses to deepening understanding of genetics cannot be tidy either. Already, and properly, there has been vigorous discussion of the use of genetic screening in the contexts of personal insurance and employment. Fears abound that genetic information will be used unfairly to discriminate against members of a population who are already cruelly disadvantaged by their genetic constitutions. To the extent that such a thing is possible, a consensus is emerging that genetic information should be confidential to individuals and their physicians (begging the question of insurance companies' standard requirement that would-be policy-holders should disclose all relevant information at the outset).

Privacy is the cornerstone of the World Medical Association's draft statement on genetic diagnosis (see page 279), which the association hopes will be accepted, possibly after amendment, during 1996. Amendment there should certainly be, for the present draft (devised by the association's Belgian constituent) is needlessly cautious, in some ways too restrictive and in others plainly unrealistic. Even the principal recommendation, that physicians should not embark on genetic diagnosis without their patients' consent, is disputable in the now-novel circumstances; should a physician be hampered in providing the best care for a patient genetically susceptible to heart disease by the patient's wish not to know the genetic facts of his or her life? A patient's privacy is paramount, but not within his or her relationship with the physician.

A proposed rider to this restriction would be even more irksome. The draft statement says that genetic diagnosis should be carried out only when there is a therapeutic or prophylactic remedy for the genetic condition identified, or when its outcome will inform "reproductive decisions". Why not also accede to patients' wish to know their status in respect to a genetically determined condition? Thus a person with late-onset Alzheimer's disease in the family would no doubt be relieved to know that he or she did not have two copies of allele-4 of the APO-E (apolipoprotein-E) gene, and otherwise would be encouraged to keep personal affairs in good order.

The underlying and false assumption is that patients should never have thrust upon them potentially disquieting information. That there should be perceptive counselling and follow-up when such information has to be communicated goes without saying (and is said often in the draft), but the drafters have underestimated the degree of public knowledge of genetics recently spread (often, sadly, in the form of over-sharp genetic determinism). They have also failed to allow for the likelihood that only when there is a wider knowledge of individuals' genetic predisposition to conditions now supposed to be intractable, such as Alzheimer's disease, will it be possible to identify life-style factors that may yet prove to be prophylactic for these conditions. In the longer run, wider genetic self-awareness will help bring about the more rational attitude towards the inevitability of death of which modern societies (and health-care systems) are in great need.

But the oddest feature of the World Medical Association's document is not a recommendation as to how physicians should behave, but part of the preamble where it is stated that prophylactic measures (to counteract the effects of deleterious genes) may lead to the survival of people "presenting altered genes" and may thus "impede the procedures of natural selection". What, one is bound to ask, has modern medicine been up to all these years? In recent decades, antibiotics have probably done more than the prophylaxis of genetically determined conditions ever will artificially to increase people's Darwinian fitness. The techniques of prenatal genetic diagnosis followed by abortion will go much further to repeal the Hardy-Weinberg law as it might apply to the balance of human genes. That practice can only grow as the repertoire of genes identifiable in utero is enlarged. If proper care is taken (on such matters as the potential of unexpected heterozygous advantage, for example), the result should be a fitter population (in the non-Darwinian sense). Is that not why physicians are in business? 